\title{
The egg-shell ultrastructure of Blatticola blattae (Graeffe, 1860) (Oxyuridomorpha: Thelastomatidae)
}

\author{
E. A. GUZEEVA, S. E. SPIRIDONOV \\ Center of Parasitology, A.N. Severtsov Institute of Ecology and Evolution, Russian Academy of Sciences, Leninskii \\ Prospect, 33, Moscow, 119071, Russia, E-mail: guzeyeva@mail.ru
}

\begin{abstract}
Summary
The egg-shell ultrastructure of Blatticola blattae has been studied under scanning and transmission electron microscopy. Similar to other studied oxyurids, it consists of five layers: a lipid layer, a chitinous layer, a vitelline layer, internal and external uterine layers. Unlike in the closely related thelastomatid Hammerschmidtiella diesingi, the external uterine layer of $B$. blattae has a honeycomb structure, the complex system of tightly joined prismatic chambers.
\end{abstract}

Keywords: scanning and transmission electron microscopy; cockroaches; honeycomb pattern of the external uterine layer; prismatic chambers

\section{Introduction}

An egg usually is the most resistant stage of the nematode life cycle that is capable to survive in stressful environmental conditions (Bird \& Bird, 1991). The multilayered egg-shell of nematodes fulfils different functions: provides the oxygen for respiration of embryo and larva; protects them from desiccation; reduces the water loss (Wharton, 1980).

The first brief report on oxyurid (Enterobius vermicularis (Linnaeus, 1758)) egg-shell ultrastructure was presented by Inatomi in 1957 (Bird \& Bird, 1991). The oogenesis and ultrastructure of the egg-shell were studied for mice pinworms Aspiculuris tetraptera (Nitzch, 1821) and Syphacia obvelata (Rudolphi, 1802), and the thelastomatid Hammerschmidtiella diesingi (Hammerschmidt, 1838) from an American cockroach Periplaneta americana (Linnaeus, 1758) by Wharton (1979a, b, c, d; 1980). Five layers of the egg-shell were distinguished in these oxyurid nematodes: lipid, chitinous, vitelline, internal uterine and external uterine, in concordance with the modified nomenclature of Bird (1971). It was presumed that three endogenous layers, such as lipid, chitinous and vitelline, are secreted by the egg itself; when two exogenous uterine layers are secreted by the uterus cells (Wharton, 1980).

Blatticola blattae (Graeffe, 1860) is a common thelastomatid nematode of the infraorder Oxyuridomorpha (order Rhabditida sensu De Ley \& Blaxter, 2002) which lives in the hindgut of a cosmopolitan synanthropic German cockroach Blattella germanica Linnaeus, 1767, its specific host. Like any other oxyurid of arthropods, B. blattae is characterized by the direct life cycle which includes an egg, four juvenile stages and an adult stage (male and female). Two juvenile stages occur in ovo (Cali \& Mai, 1965; Adamson, 1989). Pham Van Luc \& Spiridonov (1990) observed the signs of the second moult inside the egg-shell of this nematode.

Other adaptations of $B$. blattae development inside the egg-shell were described: retardation of the egg embryonic development on the 4-cell stage (Pham Van Luc \& Spiridonov, 1989); arrhenotoky - development of only males from non-fertilized eggs (Pham Van Luc \& Spiridonov, 1990). It is obvious that the stages of B. blattae life cycle, protected by the egg-shell, are crucial for the survival, dissemination and successful infestation of the host.

In the present study, the fine surface structure of $B$. blattae eggs was studied under scanning electron microscope (SEM); transmission electron microscope (TEM) was used to study the ultrastructure.

\section{Material and methods}

Cockroaches were collected in Moscow Zoo insectarium. Insects were killed with the quick decapitation and dissected, the hindgut removed and transferred into $0.9 \%$ physiological saline. Then, the hindgut was torn by needles and the nematodes were removed.

Before the fixation of live gravid females, the anterior end at pharynx level was cut off by razor blade for better permeability. Separate eggs were also isolated from females 

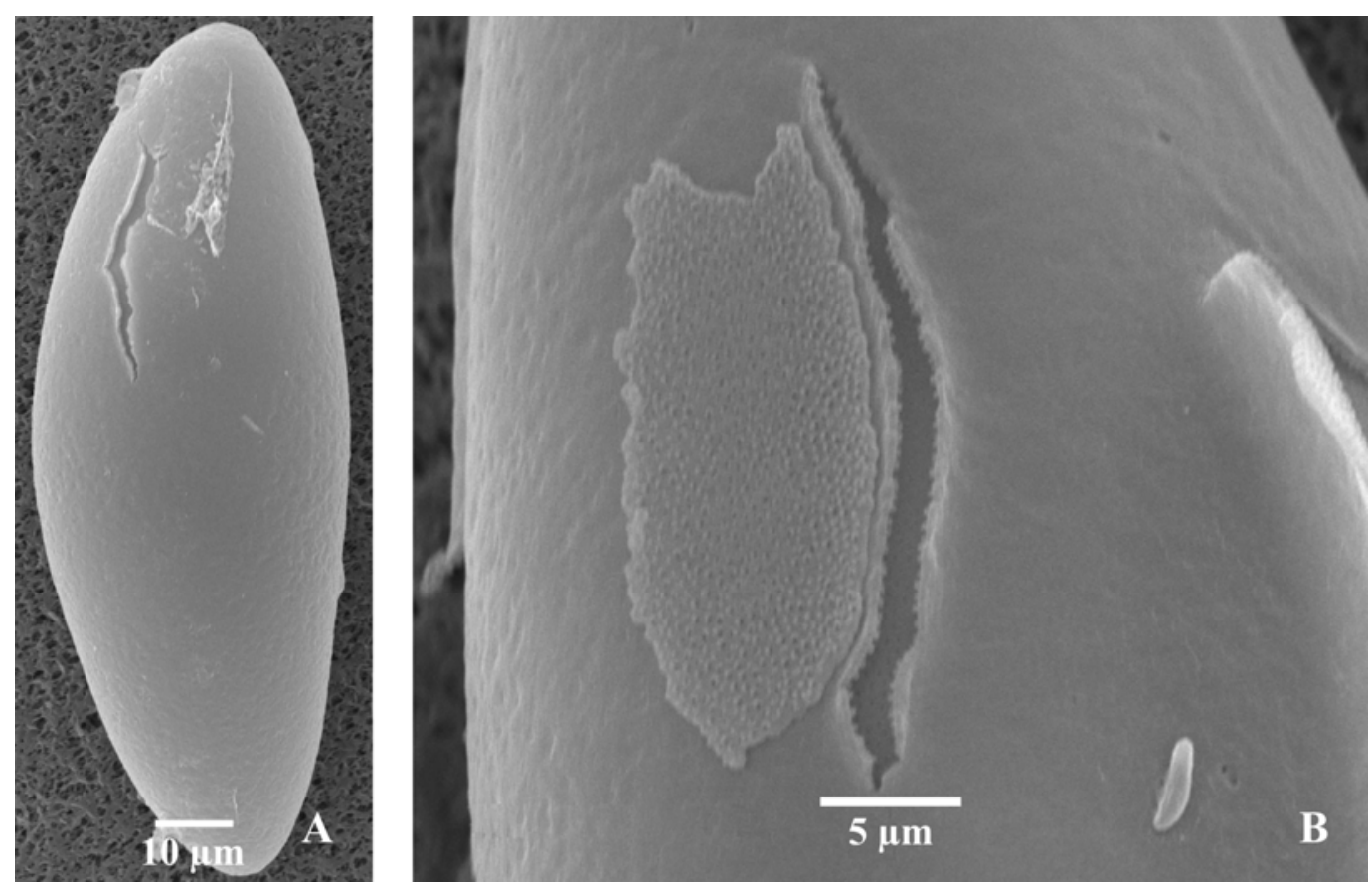

Fig. 1. The egg of Blatticola blattae (SEM). A - total view; B - flaked off and reversed up side down the external uterine layer of the shell

and fixed. Egg-shells with developing stages were broken by gentle touch of the capillary pipette with the end melted into tiny spherical tip over gas burner. Both adults and eggs were fixed for $12 \mathrm{~h}$ in $2.5 \%$ glutaraldehyde in $0.2 \mathrm{M}$ sodium cacodylate buffer $(\mathrm{pH} 7.2$ - 7.4) with $0.9 \% \mathrm{NaCl}$ and $0.5 \% \mathrm{MgCl}_{2}$; washed in a graded series $(15 \mathrm{~min}, 1 \mathrm{~h}$, $3 \mathrm{~h}$ ) of rinsing buffer; post-fixed for $4 \mathrm{~h}$ in $1 \%$ osmium tetroxide; rinsed in distilled water 3 times; stained in $1 \%$ uranyl acetate. Eggs were embedded into cubic blocks $(3 \times$ $3 \times 3 \mathrm{~mm}$ ) of $1 \%$ agarose (Wright \& Jones, 1965). After that, all fixed material was dehydrated in a series of accel- erating concentrations of ethanol and isopropanol, infiltrated and embedded in Spurr resin for $48 \mathrm{~h}$ at $60{ }^{\circ} \mathrm{C}$ (Sigma-Aldrich $^{\circledR}$, Saint Louis, Missouri, USA). Ultrathin, silver-grey sections were made with the help of an ultramicrotome Reichert-Jung 701701 (Leica Microsystems $\mathrm{GmbH}$, Wetzlar, Germany); picked up on grids with the formvar base; stained with $1 \%$ uranyl acetate and lead citrate and examined with a JEM-1011 transmission electron microscope (JEOL Ltd., Tokyo, Japan) (accelerating voltage $80 \mathrm{kV}$ ). Five eggs were studied by this method. For SEM studies the eggs were placed onto a piece of

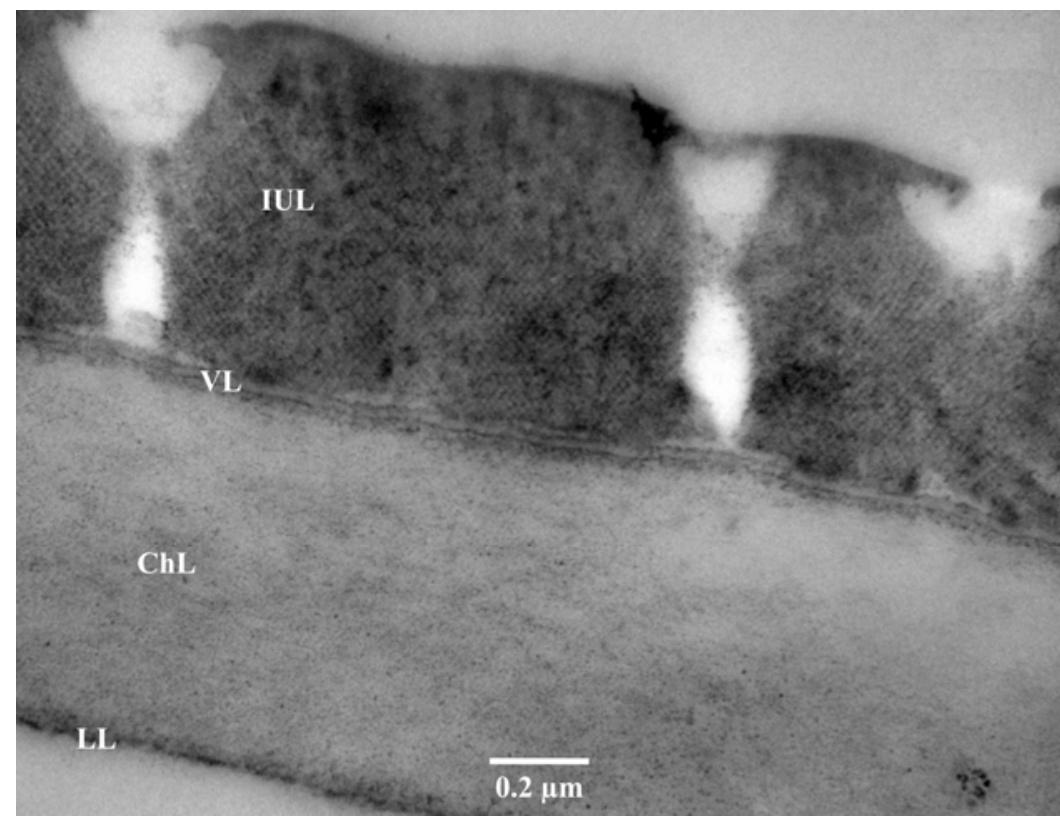

Fig. 2. Four layers of Blatticola blattae egg-shell (TEM). Abbreviations: $\mathrm{LL}$ - lipid layer; $\mathrm{ChL}$ - chitinous layer; $\mathrm{VL}$ - vitelline layer; IUL - internal uterine layer 
$0.2 \mu \mathrm{m}$-pore nylon filter (Millipore ${ }^{\mathrm{TM}}$, Billerica, Massachusetts, USA) covered by polylysine and dehydrated in grading concentrations of ethanol $(10,20,40,60,80$ and $96 \%$ ), placed in acetone, critical point dried in a HCP-2 (Hitachi ${ }^{\circledR}$, Tokyo, Japan), coated with gold and examined with a JSM-6380 LA scanning electron microscope (JEOL Ltd.) (accelerating voltage $20 \mathrm{kV}$ ).

SEM and TEM photographs were taken in the Electron Microscopy Laboratory of Biological Faculty, Moscow State University, Moscow, Russia.

\section{Results}

The eggs of $B$. blattae are elongated, without opercula, 105 $-130 \mu \mathrm{m}$ long and $45-56 \mu \mathrm{m}$ wide, sharpened to both ends (Fig. 1A). Egg-shells are ca. $2 \mu \mathrm{m}$ thick and composed of five layers: lipid, chitinous, vitelline, internal and external uterine layers.

The innermost layer of the egg-shell is a thin, without the distinct border, osmiophilic lipid layer underlying thicker chitinous layer $(0.76-0.79 \mu \mathrm{m})$ of homogeneous structure and much lower electron density (Figs 2, 4). At egg-shell polar areas the latter is thickened $(2-3$ times compared to lateral walls).

A thin lipoprotein vitelline layer is organized as a double membrane dividing the chitinous layer from the internal uterine layer $(0.7-0.74 \mu \mathrm{m}$ thick). This latter consists of tightly interwoven electron-dense fibers and discrete caverns (Figs 2, 4).

The external uterine layer of the B. blattae egg-shell is extremely fragile and flakes off from inner layers during the routine fixation techniques (Figs 1A, B, 3A). This layer is a complex construction of tightly joined but separate prismatic chambers. Each chamber is hexagonal, sometimes pentagonal, $(0.87-0.91 \times 0.59-0.67 \mu \mathrm{m})$ in the tangential section of an egg-shell and rectangular $(0.58-$ $0.6 \times 0.49-0.53 \mu \mathrm{m})$ in the section across the shell wall (Figs 3B, C, 4). The chambers are with walls $30-50 \mathrm{~nm}$ thick and composed from friable material of middle electron density. Each chamber is divided from the neighbouring one by $8-15 \mathrm{~nm}$ wide space, and all together form a honeycomb pattern of the external uterine layer (Fig. 4).
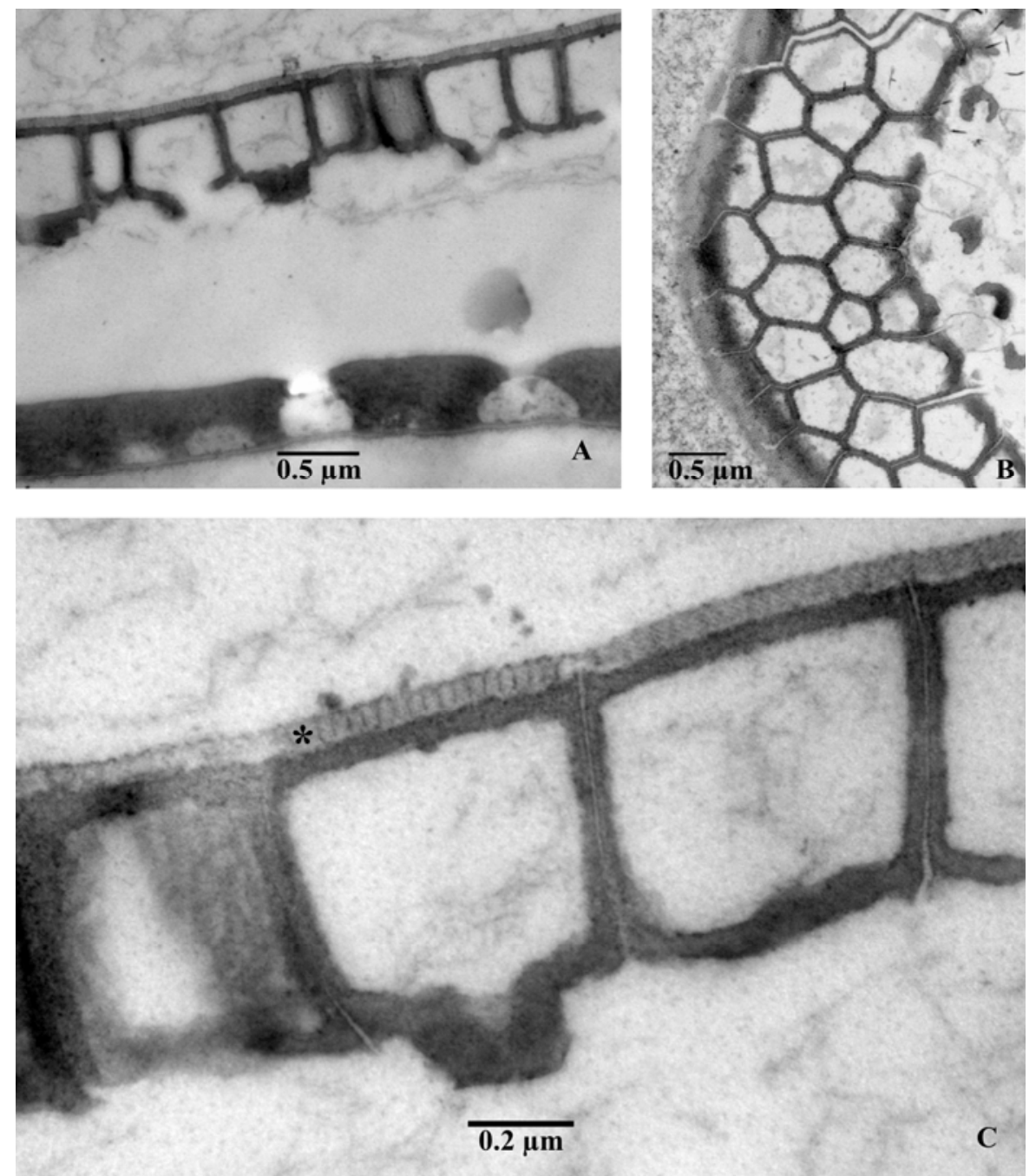

Fig. 3. The external uterine layer of Blatticola blattae egg-shell (TEM). A - separation of the external uterine layer from the other four layers of the shell during fixation; $\mathrm{B}$ - tangential section of the shell; $\mathrm{C}$ - cross section of the shell. Surface coating of the external uterine layer is designated by asterisk $(*)$ 


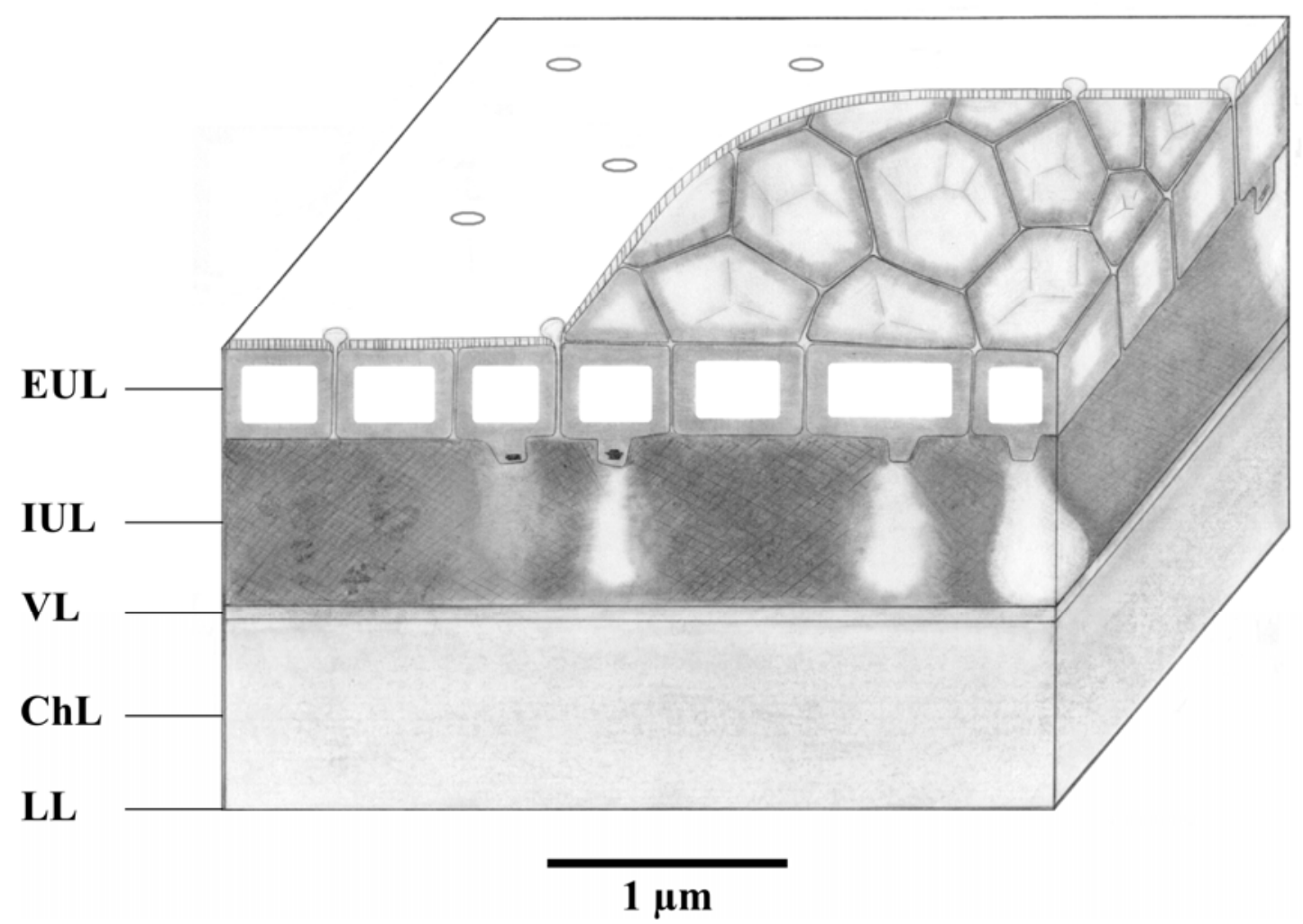

Fig. 4. The structure of Blatticola blattae egg-shell (Graphical scheme). Abbreviations: LL - lipid layer; ChL - chitinous layer; $\mathrm{VL}$ - vitelline layer; IUL - internal uterine layer; EUL - external uterine layer

On the inner side of the latter, some chambers have distinct projections $(0.23-0.26 \times 0.13-0.17 \mu \mathrm{m})$ (Figs 1B, 3A, $\mathrm{C}, 4)$. Some of these projections bear electron-dense particles. As these projections reach the surface of the internal uterine layer, it can be presumed that it serves to secure the attachment of these two uterine layers.

The outer surface of the external uterine layer is covered with a thin, fibrous, electron-light coating up to $63 \mathrm{~nm}$ thick (Figs 3A, C, 4). The cross-section of this coating demonstrates vertical electron-dense $7-8 \mathrm{~nm}$ wide bands with $21-25 \mathrm{~nm}$ gaps between. The layer is pierced by pores where adjacent chambers touch each other.

\section{Discussion}

To date, the egg-shell ultrastructure of parasitic nematodes from different taxonomic groups has been examined in detail. It was found that nematodes from the orders Trichinellida and Rhabditida (infraorders Tylenchomorpha, Rhabditomorpha and some of Ascaridomorpha) are characterized by endogenous three-layered egg-shell structure (Waller, 1971; Bird \& McClure, 1976; Solomon \& Grigonis, 1976; Wharton \& Jenkins, 1978; Wharton, 1979e). Meanwhile, the Ascaridomorpha species of Ascaris Linnaeus, 1758 and Heterakis Dujardin, 1845 possess additional exogenous uterine layer (Foor, 1967; Lee \& Lešt'an, 1971). The representatives of the infraorder Oxyuridomorpha have two pronounced internal and external uterine layers (Wharton, 1979b, c, d). Ovoviviparous filariid nematodes (infraorder Spiruromorpha) give birth to first stage juveniles (or microfilariae) developing within the surface coat (so called 'shell') retained as a sheath. Similar to egg-producing nematodes, the surface coat, which is thought to be secreted by ovarian cells, together with the original oolemma, separates from the surface of the oocyte under the stimulus of fertilization and a new oolemma is produced. However, their shells lack the lipid and chitinous layers (McClaren, 1973).

The egg-shell ultrastructure of $B$. blattae is characterized by the same basic pattern shown for A. tetraptera, $S$. obvelata and $H$. diesingi (Wharton, 1979b, c, d) (Table 1).

It was demonstrated before that general structure of endogenous layers is uniform throughout all studied oxyurids (Wharton, 1980).

The lipid layer is the innermost layer of the nematode eggshell. This layer is formed by material which may be released at the surface of the fertilized oocyte. It was presumed earlier that it is responsible for the impermeability in some nematode egg-shells (Wharton, 1980; Bird \& Bird, 1991). This layer also becomes more permeable before hatching of some nematodes that plays an important role in the hatching mechanism (Perry \& Clark, 1981). Unlike the majority of studied nematodes, the lipid layer of oxyurids is always a very thin osmiophilic layer without the distinct border. In parasitic nematodes of vertebrates such as ascarids (infraorder Ascaridomorpha) or trichinellids (order 
Table 1. Comparative thickness of separate layers of oxyurid egg-shells

\begin{tabular}{|c|c|c|c|c|}
\hline Character & $\begin{array}{c}\text { B. blattae } \\
\text { (Original data) }\end{array}$ & $\begin{array}{c}\text { H. diesingi } \\
\text { (Wharton, 1979b) }\end{array}$ & $\begin{array}{c}\text { A. tetraptera } \\
\text { (Wharton, 1979a) }\end{array}$ & $\begin{array}{c}\text { S. obvelata } \\
\text { (Wharton, 1979c) }\end{array}$ \\
\hline Lipid layer & 0.011 & 0.046 & 0.04 & 0.018 \\
\hline Chitinous layer & $0.76-0.79$ & 1.0 & 1.7 & 0.57 \\
\hline Vitelline layer & 0.022 & 0.015 & 0.046 & 0.01 \\
\hline $\begin{array}{l}\text { Internal } \\
\text { uterine layer }\end{array}$ & $0.7-0.74$ & 0.5 & 1.16 & 0.11 \\
\hline $\begin{array}{l}\text { External } \\
\text { uterine layer }\end{array}$ & $0.49-0.53$ & 0.01 & 0.013 & 0.01 \\
\hline $\begin{array}{l}\text { Fibrous coating on } \\
\text { egg-shell surface }\end{array}$ & + & + & + & + \\
\hline $\begin{array}{l}\text { Presence/ absence of } \\
\text { operculum }\end{array}$ & - & + & + & + \\
\hline $\begin{array}{l}\text { Overall thickness of } \\
\text { egg-shell }\end{array}$ & 2.038 & 1.571 & 2.959 & 0.718 \\
\hline Egg size & $105-130 \times 45-56$ & $85-87 \times 33-35$ & $84-96 \times 34-46$ & $115 \times 35$ \\
\hline
\end{tabular}

Note: all measurements are in $\mu \mathrm{m}$

Trichinellida) the lipid layer is much thicker and occupies up to quarter of total egg-shell thickness (Foor, 1967; Lee \& Lešt’an, 1971; Solomon \& Grigonis, 1976; Wharton \& Jenkins, 1978; Wharton, 1979e). The lipid layer in plantparasitic nematodes of the infraorder Tylenchomorpha was found thickening at the shell poles and having a series of lipoprotein membranes associated with it (Bird \& McClure, 1976).

The chitinous layer is often the thickest layer of the eggshell. It provides its structural strength (Bird \& Bird, 1991). The chitinous layer usually consists of chitin-protein complexes comprising chitin microfibrils embedded in a protein matrix (Wharton, 1980). In trichinellid nematodes this layer has a helicoidal architecture representing parabolic arcs and lamellae (in Trichuris suis Schrank, 1788) or a 'pillar and beam-like' network on its outer portion (in Capillaria hepatica (Bancroft, 1893)) (Solomon \& Grigonis, 1976; Wharton \& Jenkins, 1978). In Ascaridomorpha this layer is characterized by non-helicoidal architecture with randomly or parallel arranged fibrils (Foor, 1967; Lee \& Lešt'an, 1971; Wharton, 1979e). In Tylenchomorpha it also represents a chitin-protein non-helicoidal complex (Bird \& McClure, 1976). According to Wharton, in oxyurids it consists of chitin and non-protein material (Wharton, 1980). The unique feature of B. blattae egg-shell is the presence of the strongly developed internal uterine layer with the thickness nearly equal to that of the chitinous one. The vitelline layer is derived from the oolemma which is a vitelline membrane of the fertilized oocyte (Bird \& Bird,
1991). It is always characterized by a membrane-like appearance and, as well as the lipid layer of oxyurids, is one of the thinnest layers of an egg-shell (Wharton, 1979b, c, d). In fully formed egg-shells, with only three endogenous layers and the vitelline layer as the outer layer of the shell, this latter is thick and bears minute projections with strands of particulate material adhering to its outer surface (Bird \& McClure, 1976; Wharton \& Jenkins, 1978; Wharton, 1979e).

The uterine layers have a complex structure and define an external relief of the nematode egg-shell (Bird \& Bird, 1991). A uterine layer of ascaridomorphs (Ascaris lumbricoides Linnaeus, 1758, A. suum Goeze, 1782 and Heterakis gallinarum (Schrank, 1788)) consists of a fibrous glycoprotein, which in the genus Ascaris represents a mammilated appearance (Foor, 1967; Lee \& Leštan, 1971). The oxyurid internal uterine layer usually has a fibrous or granular appearance and contains caverns organized or not into interconnecting system. So, in B. blattae and $S$. obvelata the internal uterine layer has a fibrous structure, while in A. tetraptera and $H$. diesingi it demonstrates a granular structure. In A. tetraptera the caverns form an interconnecting system whether in three other studied species they appear to be discrete (Wharton, $1979 b, c, d)$. Unlike B. blattae, the external uterine layer thickness of $A$. tetraptera, $H$. diesingi and $S$. obvelata does not exceed the thickness of lipid and vitelline layers. Wharton marked the presence of special "strands of particulate material adhering to the outer surface of the 
external uterine layer" (1979 b, c, d). The similar structures were reported on the surface of $B$. blattae egg-shell.

The most remarkable feature of Blatticola blattae egg-shell is the structure of the external uterine layer which consists of closely situated but separate prismatic chambers. Such organization of the outer layer was described neither for oxyurids from vertebrate hosts (Aspiculuris and Syphacia) nor for more closely related thelastomatids of cockroaches (Hammerschmidtiella and Leidynema (Leidy, 1850)). The recent phylogenetic analysis of Blatticola relationships has revealed a quite isolated position of this genus within the superfamily Thelastomatoidea Travassos, 1929 (Spiridonov \& Guzeeva, 2009). While the genera Hammerschmidtiella and Leidynema are closely related members of the same clade, Blatticola is clustering closer to the basal nodes of the thelastomatid lineage (Spiridonov \& Guzeeva, 2009).

$B$. blattae is an oxyurid nematode with unique set of morphological and ecological features: monodelfic female reproductive system, conical tail without distinct tail filament in both sexes, parasitism in blattelid host. Now we can add a peculiar structure of the egg-shell to this list of specific features of $B$. blattae, as its ultrastructure differs significantly from that of other studied oxyurids.

\section{Acknowledgements}

Authors would like to acknowledge a special debt of gratitude to Dr Vladimir V. Yushin, head of the Laboratory of Embryology, Institute of Marine Biology FEB RAS, Vladivostok, Russia who provided us with the protocol of nematode fixation for TEM. We are grateful to Drs Julia K. Zograf and Svetlana V. Polevova and staff members of the Laboratory of Electron Microscopy of Biological Faculty of Moscow State University who taught the first author TEM techniques. We thank Dr Mikhail V. Berezin and staff members of Moscow Zoo insectarium for providing insect hosts. This work was supported by the grant of the Russian Foundation of Basic Research № 11-0400590a.

\section{References}

AdAmson, M. L. (1989): Evolutionary Biology of the Oxyurida (Nematoda): Biofacies of a Haplodiploid Taxon. Adv. Parasit., 28: 175 - 227

BIRD, A. F. (1971): The Structure of Nematodes. New York, USA, Academic Press, Inc., 318 pp.

BIRD, A. F., BIRD, J. (1991): The Structure of Nematodes. San Diego, USA, Academic Press, Inc., 316 pp.

Bird, A. F., McClure, M. A. (1976): The tylenchid (Nematoda) egg-shell: structure, composition and permeability. Parasitology, 72: $19-28$

CALI, C. T., MAI, W. F. (1965): Studies on the development of Blatticola blattae (Graeffe, 1860) Chitwood, 1932 within its host, Blattella germanica L. Proc. Helm. Soc. Wash., 32 (2): 164 - 169

\section{RECEIVED NOVEMBER 18, 2011}

De Ley, P., Blaxter, M. (2002): Systematic Position and Phylogeny. In LEE D. L. (Ed) The Biology of Nematodes. London, UK: Taylor \& Francis, pp. $1-30$

FOOR, W. E. (1967): Ultrastructural aspects of oocyte development and shell formation in Ascaris lumbricoides. $J$. Parasitol., 53 (6): 1245 - 1261

LEE, D. L., LEŠŤAN, P. (1971): Oogenesis and egg-shell formation in Heterakis gallinarum (Nematoda). J. Zool., 164: $189-196$

MCClaren, D. J. (1973): Oogenesis and fertilization in Dipetalonema viteae (Nematoda: Filarioidea). Parasitology, 66: 465 - 472

Perry, R. N., Clarke, A. J. (1981): Hatching mechanisms of nematodes. Parasitology, 83: 435 - 449

Pham, V. L., SPIRIDONOV, S. E. (1989): Peculiarities of biology of oxyurid Blatticola blattae - a parasite of the German cockroach. Materialy nauchnoi conferencii VOG, 38: $232-238$

PhAM, V. L., SPIRIDONOV, S. E. (1990): Experimental evidence of arrhenotoky in the nematode Blatticola blattae (Oxyurida; Thelastomatidae). Helminthologia, 27 (1): 8 13

Solomon, G. B., Grigonis, G. J. (1976): Capillaria hepatica: relation of structure and composition of egg-shell to antigen release. Exp. Parasitol., 40: 298 - 307

Spiridonov, S. E., Guzeeva, E. A. (2009): Phylogeny of nematodes of the superfamily Thelastomatoidea (Oxyurida) inferred from LSU rDNA sequence. Russ. J. Nematol., 17 (2): $127-134$

WALLER, P. J. (1971): Structural differences in the egg envelopes of Haemonchus contortus and Trichostrongylus colubriformis (Nematoda: Trichostrongylidae). Parasitology, 62: $157-160$

Wharton, D. A. (1979a): Oogenesis and egg-shell formation in Aspiculuris tetraptera Schulz (Nematoda: Oxyuroidea). Parasitology, 78: 131 - 143

WharTon, D. A. (1979b): The structure of the egg-shell of Aspiculuris tetraptera Schulz (Nematoda: Oxyuroidea). Parasitology, 78: 145 - 154

Wharton, D. A. (1979c): The structure and formation of the egg-shell of Hammerschmidtiella diesingi Hammerschmidt (Nematoda: Oxyuroidea). Parasitology, 79: 1 - 12 Wharton, D. A. (1979d): The structure and formation of the egg-shell of Syphacia obvelata Rudolphi (Nematoda: Oxyurida). Parasitology, 79: 13 - 32

WharTon, D. A. (1979e): The structure of the egg-shell of Porrocaecum ensicaudatum (Nematoda: Ascaridida). Int. J. Parasitol., 9: 127 - 131

Wharton, D. A. (1980): Nematode egg-shells. Parasitology, 81: $447-463$

Wharton, D. A., JENKINS, T. (1978): Structure and chemistry of the egg-shell of a nematode (Trichuris suis). Tissue Cell, 10: 427 - 440

Wright, K. A., JONES, N. O. (1965): Some techniques for the orientation and embedding of nematodes for electron microscopy. Nematologica, 11 (1): $125-131$

ACCEPTED APRIL 19, 2012 